lence of mental disorder, ${ }^{5}$ and accepting that some individuals with congenital adrenal hyperplasia may struggle to adapt, we conclude that the women with congenital adrenal hyperplasia in our small study are psychologically robust. Future studies must consider factors contributing to good psychological outcome, including timing of surgery and communication with parents and patients.

Contributors: JFM, JHL, and GC originated and designed the study. JFM collected the data. JFM and HM analysed and interpreted the data and drafted the manuscript. GC, JHL, and JFM critically revised the manuscript. JHL supervised the study. JFM is guarantor.

Funding: No additional funding.

Competing interests: None declared.

Ethical approval: Research ethics committee for the Central Middlesex Hospital.

Creighton S, Minto C. Managing intersex. BMJ 2001;323:1264-5.

2 Meyer-Bahlburg HFL. Gender and sexuality in classic congenital adrenal hyperplasia. Endocrinol Metab Clin North Am 2001;30:155-71,VIII

\section{What is already known on this topic}

Intersex children may have increased prevalence of psychiatric morbidity; research on adult psychological outcomes is limited despite fears that the condition may adversely affect psychosocial adjustment

\section{What this study adds}

Most women with congenital adrenal hyperplasia have good long term psychological outcome, with no dramatic increase in psychological morbidity, good social adjustment, and no deficit in self esteem

3 Cooper P, Osborn M, Gath D, Feggetter G. Evaluation of a modified selfreport measure of social adjustment. BJPsych 1992:141:68-75.

Kessler RC, McGonagle KA, Zhao S, Nelson CB, Hughes M, Eshleman S, et al. Lifetime and 12-month prevalence of DSM-III-R psychiatric disorders in the United States: results from the national comorbidity survey. Arch Gen Psychiatry 1994;51:8-19.

5 Slijper FME, Drop SL, Molenaar JC, de Muinck Keizer-Schrama MD. Long term psychological evaluation of intersex children. Arch Sex Behav 1998;27:125-45.

(Accepted 1 December 2004)

doi 10.1136/bmj.38334.427361.D3

\title{
Commentary: A support group's perspective
}

\author{
Melissa L Cull
}

Living with congenital adrenal hyperplasia (CAH) poses many challenges, especially for women-the issues of genital surgery, disclosure, informed consent, weight, and general wellbeing not to mention having a chronic condition that is life threatening. Not only does working as a research assistant provide insight into how the medical profession views these conditions, but also working voluntarily with support groups for $\mathrm{CAH}$ for many years and also having CAH myself gives me insight that few doctors or psychologists will ever see or experience.

More research is now being done into the psychological long term outcomes of women with $\mathrm{CAH}$, and that is good to see. ${ }^{1}$ Although I am glad that the small cohort of women in the paper generally had good outcomes, support groups tend to hear a somewhat different story. ${ }^{2}$ Perhaps only people who are dissatisfied with their treatment come to support groups-though going by the rarity of the condition and the comparative number of members it shows many are not surprisingly dissatisfied-but we get people who are satisfied as well. Long term qualitative and quantitative research is important, but the difficulty is getting a large number of participants.

Depression and stress are often reported, particularly to do with relationships, with sexual difficulties after surgery and weight problems associated with steroid replacement. Non-disclosure, shame, secrecy, and stigmas attached to having ambiguous genitalia, an intersex condition, and surgery to "normalise" all place a heavy toll on a woman's psychological wellbeing. What is normal, anyway, if everyone is individual and different?

As more long term surgical outcome studies are done, ${ }^{3}$ it can be seen that the result is psychological as well as physical impact. Genital surgery as young children that was not personally consented to often causes compromised genital sensation and inability to orgasm, and functional damage can give rise to feelings of loss of body ownership. Surgery is often cited as "one stage fix all," but many women need repeat procedures and ongoing dilatation treatment, which can be a constant reminder of difference.

Many women with CAH avoid social situations, frightened that people will find out they have a rare misunderstood condition. Fear of rejection conditioned by parents and the medical profession forces them to avoid intimate contact let alone enter into sexual relationships. Body image for women is important, ${ }^{4}$ and it is dependent on how well the family adjust to having a daughter with CAH as well as how many genital examinations and how they are done. In turn, body image and self esteem affect avoidance of social situations.

A recent paper questions whether it is better to bring up children with such conditions without surgical intervention until they are old enough to be informed and consent themselves but also stipulates multidisciplinary care to reduce any psychological problems. ${ }^{5}$

Although most women with CAH do cope well, others find it difficult. Much stigma is still attached to seeking psychological help and particularly so with intersex conditions. Multidisciplinary one stop patient centred care with endocrinology, gynaecology, and psychology expert teams are now gradually becoming the excellent cornerstone of care for CAH. Women who attend these clinics such as the authors' are coping much better psychologically. Were the study to be repeated in conventional clinics, I am sure the results would unfortunately be less positive.

Competing interests: None declared.

1 Morgan JF, Murphy H, Lacey JH, Conway GS. Long-term psychological outcomes of women with congenital adrenal hyperplasia: cross-sectional survey. BMJ 2005; doi 10.1136/bmj.38334.427361.D3.

2 Cull M. Treatment of intersex needs open discussion. BMJ 2002:324:919. 3 Creighton SM, Minto CL. Managing intersex. BMJ 2001;323:1264-5.

4 May B, Boyle M, Grant D. A comparative study of sexual experiences: women with diabetes and women with congenital adrenal hyperplasia. $J$ Health Psychol 1996;1:479-92.

5 Ahmed SF, Morrison S, Hughes IA. Intersex and gender assignment: the third way? Arch Dis Child 2004;89:847-50.

doi $10.1136 /$ bmj.38365.883843.79
17 Newton Road, Lichfield, Staffordshire, WS13 7EF Melissa L Cull founder of the adrenal hyperplasia network (www.ahn.org.uk)

Melissa.cull@ mlcull.demon.co.uk 